FACTA UNIVERSITATIS

Series: Physical Education and Sport Vol. 15, N ${ }^{\circ}$ 3, 2017, pp. 453 - 466

https://doi.org/10.22190/FUPES1703453L

Research article

\title{
A PILOT ANALYSIS: CAN THE BULGARIAN SPLIT-SQUAT POTENTIATE SPRINT ACCELERATION IN STRENGTH-TRAINED MEN?
}

\author{
UDC 796.012.11
}

\section{Robert Lockie, Ashley Orjalo, Matthew Moreno}

Department of Kinesiology, California State University, Fullerton, Fullerton, USA

\begin{abstract}
This study determined whether a five repetition-maximum Bulgarian split-squat (5RM BSS) could potentiate a 0-5, 0-10, and 0-20 m (meter) sprint performance. Seven men were assessed in the 5RM BSS (a linear position transducer measured peak power [PP] and force [PF] for each leg), and completed two post activation potentiation (PAP) sessions. One session involved a control condition $(C C)$ of 4 minutes $(\mathrm{min})$ rest; the other the 5RM BSS. Participants were assessed in baseline sprints, and sprints of 15 seconds, 2, 4, 8, 12, and 16 min post-PAP intervention. A repeated measures ANOVA $(p<0.05)$ calculated significant changes in sprint times. The best potentiated time for each interval was also compared to the baseline. Spearman's correlations $(\rho ; p<0.05)$ calculated relationships between absolute and relative strength, $P P$ and $P F$, with percent potentiation in sprint times. The BSS did not potentiate speed at any time, although there was great individual variation. The best 0-5 $\mathrm{m}$ time was significantly different from the baseline $(p=0.022)$, with no differences between $P A P$ conditions. Significant correlations were found between strength and sprint potentiation at 16 min for the 0-5 m interval, and at 8 min and the best times for the 0-20 m interval ( $\rho=$ 0.786 to -0.893). There were correlations between $P P$ and $P F$ for each leg with sprint potentiation from 2-12 min across all intervals $(\rho=-0.786$ to -0.964$)$. Stronger individuals who generate greater PP and PF in a 5RM BSS will be more likely to potentiate 20-m sprint performance.
\end{abstract}

Key words: PAP, unilateral strength, peak power, peak force, linear position transducer

Received December 11, 2017 / Accepted January 16, 2018

Corresponding author: Robert George Lockie

California State University, Fullerton Department of Kinesiology 800 N State College Blvd Fullerton, CA 92831 USA

Phone: +1 657-278-4971•E-mail: rlockie@fullerton.edu 


\section{INTRODUCTION}

Post activation potentiation (PAP), a phenomenon where muscle performance is augmented due to contraction history, is often a goal in strength and power training programs (Hodgson, Docherty, \& Robbins, 2005; Tillin \& Bishop, 2009). Performance improvements have been associated with an increase in the rate of force development within the muscles (Hodgson et al., 2005), and most reviews have intimated that there are two major mechanisms responsible for the PAP effect (Hodgson et al., 2005; Tillin \& Bishop, 2009; Wilson et al., 2013). Firstly, there is the phosphorylation of myosin regulatory light chains that results from the prior muscular contraction, which makes the actin and myosin more sensitive to $\mathrm{Ca}^{2+}$ (Hodgson et al., 2005; Tillin \& Bishop, 2009). The second factor relates to the increased recruitment of higher order motor units, which theoretically should result in an increase in fast-twitch muscle fiber contribution to a contraction (Tillin \& Bishop, 2009). The force a muscle can produce following prior contractile activity is a product of the balance between fatigue and potentiation, which has important implications for training program design.

Complex training, which involves completing a strength exercise (e.g. a resistance exercise with a load $\geq 85 \%$ of an individual's one-repetition maximum [RM]), followed by a power-based exercise (e.g. a jump), is a method by which coaches can design programs to encourage PAP in their athletes (Ebben, 2002). Recently, there have been investigations of complex pairs designed to potentiate the dynamic action of sprinting. However, there have been conflicting findings as to whether sprint performance can be potentiated by a strength exercise. Chatzopoulos et al. (2007) reported that 10 repetitions at $90 \%$ of $1 \mathrm{RM}$ of the back half-squat led to faster 0-10 $\mathrm{m}$ and 0-30 sprint times following 5 minutes (min) recovery in team sport athletes. Parallel back squats performed with 85\% (Rahimi, 2007) and 90-91\% (Bevan et al., 2010; McBride, Nimphius, \& Erickson, 2005) of 1RM, improved the 40-m sprint time after $4 \mathrm{~min}$ in soccer players (Rahimi, 2007) and Division III football players (McBride et al., 2005), and 0-5 $\mathrm{m}$ and 0-10 $\mathrm{m}$ sprint times when recovery periods were individualized to find the best potentiated time in professional rugby players (Bevan et al., 2010). In contrast, Lim \& Kong (2013) found that performing a 3RM back squat did not improve 30-m sprint performance after $4 \mathrm{~min}$ in well-trained track and field athletes. Both McBride et al. (2005) and Crewther et al. (2011) used a 3RM back squat for Division III football players and rugby players, respectively. The strength exercises did not enhance 0-5 $\mathrm{m}$ (Crewther et al., 2011), 0-10 m (Crewther et al., 2011; McBride et al., 2005), or 0-30 m times (McBride et al., 2005).

One of the potential limiting factors in studies investigating PAP effects upon sprinting was that the strength exercises used were bilateral (Bevan et al., 2010; Chatzopoulos et al., 2007; Crewther et al., 2011; Lim \& Kong, 2013; McBride et al., 2005; Rahimi, 2007; Yetter \& Moir, 2008). Yetter \& Moir (2008) stated that a back squat may not provide a movementspecific stimulation to the muscles required for sprinting. Sprinting is a cyclic, unilateral action, where the individual alternates between single-limb support and flight (Lockie et al., 2013). To run faster, the individual must be able to transfer their general strength to the sprint step by ensuring that the nervous system can control the augmented force output (Tsimahidis et al., 2010). This could result in greater force and power generation within the sprint step, and indeed strength and power training can improve speed (Lockie, Murphy, Schultz, Knight, \& Janse de Jonge, 2012; Speirs, Bennett, Finn, \& Turner, 2016). To 
increase the specificity of resistance training for speed development, it is important to incorporate unilateral exercises (Lockie et al., 2012; Speirs et al., 2016). One example of a unilateral strength exercise is the Bulgarian split-squat (BSS), which involves an individual performing a single-leg squat while the non-working leg is supported on a bench (McCurdy, Langford, Cline, Doscher, \& Hoff, 2004). Due to the specificity of the movement when compared to the sprint step (Speirs et al., 2016), the BSS could be used to potentiate sprint performance. However, there is currently no research that has investigated whether a unilateral strength exercise such as the BSS can potentiate sprint acceleration in trained individuals.

Therefore, this pilot study investigated whether the BSS can invoke a PAP response for a 20-m sprint, including the 0-5 m, 0-10 m, and 0-20 m intervals, when compared to a control condition (CC) of rest in strength-trained men. This study had two goals. The first goal was to ascertain whether the BSS could potentiate sprint performance from the immediate completion of the exercise to $16 \mathrm{~min}$ post. Secondly, to determine relationships between absolute and relative strength, as well as peak power (PP) and peak force (PF) recorded during the BSS, with any PAP effects that resulted from the BSS. It was hypothesized that the SS would potentiate 20 -m sprint performance, and this would occur within the time frame of 4-8 min for most participants. In addition to this, the relationship analysis would illustrate that participants who were stronger, and generated greater PP and PF within the BSS, would experience greater PAP effects when sprinting.

\section{METHODS}

\section{Participants}

Seven strength-trained males (age $=23.43 \pm 1.51$ years; height $=1.77 \pm 0.05 \mathrm{~m}$; body mass $=77.76 \pm 10.30$ kilograms $[\mathrm{kg}]$ ) were recruited for this pilot analysis. Participants were required to: be currently involved in strength training ( $\geq$ three hours per week); have a strength training history ( $\geq$ two times per week) extending over the previous year; be familiar with the BSS; maintain their normal physical activity and diet for the duration of the study; and not have any medical conditions compromising study participation. The methodology was approved by the institutional ethics committee. Participants received an explanation of the study, including the risks and benefits of participation, and written informed consent was obtained prior to testing.

\section{Procedures}

Three testing sessions were used for this study (Figure 1), and all testing was conducted in a teaching gym at the university. At least 48-72 hours separated each testing session (Crewther et al., 2011; Lockie et al., 2016; Turner, Bellhouse, Kilduff, \& Russell, 2015), which were completed at the same time of day across the sessions for each participant, depending on their availabilities. Session 1 involved determination of the 5RM for the BSS. The orders of the two PAP testing sessions (CC and SS) were randomized. At the start of the first testing session, the participant's age, height, and body mass were recorded. Height was measured barefoot using a portable stadiometer (seca, Hamburg, Germany), while body mass was recorded by electronic digital scales (Tanita 
Corporation, Tokyo, Japan). Each session featured the same dynamic warm-up, which consisted of $5 \mathrm{~min}$ of jogging at a self-selected pace on a treadmill, $10 \mathrm{~min}$ of dynamic stretching, and progressive speed runs $(\sim 60 \%, 70 \%, 80 \%$, and $90 \%$ of perceived maximum) over $20 \mathrm{~m}$. Next, depending on the session, participants either progressed into strength testing (session 1), or completed the baseline 20-m sprints (sessions 2 and 3). Participants wore their own athletic shoes for all the tests. No knee wraps, weightlifting belts, or supportive garments were permitted during performance of the BSS. In the 24-hour period prior to any session, participants abstained from intensive exercise.

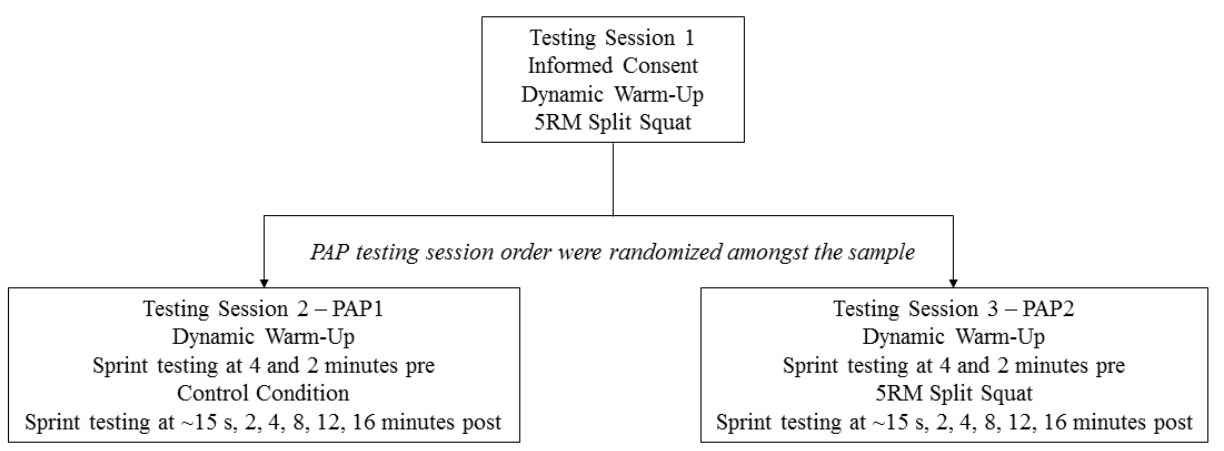

Fig. 1 Schematic representation of the study design. 1RM: one-repetition maximum. 5RM: five-repetition maximum. PAP: post-activation potentiation

\section{RM Bulgarian Split-Squat (BSS) Strength Test}

The procedures for the 5RM BSS were adapted from McCurdy et al. (2004), and performed with an Olympic bar and plates within a power rack (American Barbell, San Diego, CA). A gym bench (American Barbell, San Diego, CA) supported the leg not completing the lift, and positioned so that participants could place the top of the foot on the bench to ensure the working leg was isolated to perform the BSS (Figure 2). Both legs were assessed, and the order of which leg was tested first was randomized amongst the sample. The 5RM load was selected for strength testing and the PAP condition as it was recommended and used in lower-body strength training (Baker, 2007; Lockie et al., 2012) and PAP research (Rahimi, 2007; Till \& Cooke, 2009; Tsimahidis et al., 2010). Participants were to descend until the top of the thigh of the working leg was parallel to the floor before ascending. This was visually assessed by the investigators. Participants were given verbal cues on when they were to halt the down phase and begin the up phase of the BSS (Lockie et al., 2012). The pins were adjusted in the rack and placed as close as possible to the bottom of the final position of the bar. The second leg was tested immediately after the first leg, and 3 min recovery was provided between collective attempts. To determine the 5RM, participants completed 10 repetitions using approximately $40 \%$ of the perceived $1 \mathrm{RM}$ on the first set, followed by a set of 5 repetitions after adding 10-20\% of weight. Next, participants completed their first attempt at the 5RM (McCurdy et al., 2004). This process continued until the participants were unable to successfully perform a $5 \mathrm{RM}$, which occurred within 5 attempts. The investigators observed the participants' working leg and the barbell for proper 
technique (McCurdy et al., 2004). If posterior displacement of the barbell occurred on the descent with no anterior movement of the knee joint, the lift was determined to be unsuccessful. Failure to descend to the appropriate position for all repetitions also terminated the test. The same load was lifted by both legs; failure on one leg resulted in test termination. The last successful load lifted was taken as the measure of absolute strength. The 5RM BSS was also ratio scaled relative to body mass via the formula: relative load $\left(\mathrm{kg} \cdot B M^{-1}\right)=5 R M$ BSS.body mass $^{-1}$.

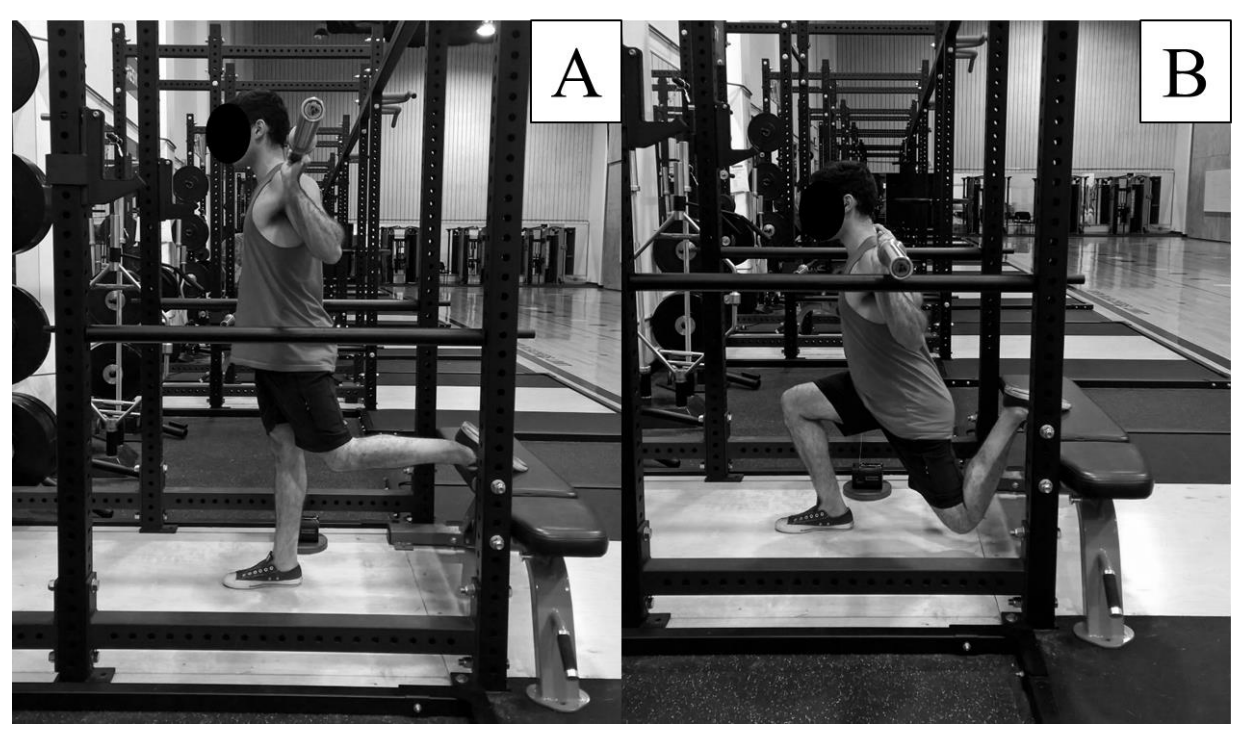

Fig. 2 Start and finish (A) and bottom (B) positions in the Bulgarian split-squat when performed by the right leg within a power rack

Power and force was measured during the BSS by a GymAware Powertool linear position transducer (Kinetic Performance Technology, Canberra, Australia). The transducer featured a spring-loaded retractable cable that passed around a spool integrated with an optical encoder (Drinkwater, Moore, \& Bird, 2012). The external end of the cable was attached on the inside of the barbell, and the transducer was then placed on the floor directly underneath the bar. The magnetic bottom was positioned on a weight plate to ensure the unit did not move during the BSS. The cable provided no resistance to the bar, and the encoder recorded the movement of the bar for every 3 millimeters of displacement. Barbell and participant mass was entered into the software so that PP and PF could be calculated. Data for each repetition was collected and stored on an iPad handheld device (Apple Inc., Cupertino, California), before being uploaded to an online database. Data was then extracted from this database, and the mean PP and PF from the 5 repetitions recorded for each leg was used for analysis. 


\section{PAP Testing}

Following the dynamic warm-up, each PAP session involved the performance of a single 20-m sprint at $4 \mathrm{~min}$ before and $2 \mathrm{~min}$ before the strength set (Crewther et al., 2011; Lockie et al., 2016). These two sprints were averaged and set the baseline for the sprints following the CC or BSS. Sprint time was recorded to the nearest $0.001 \mathrm{~s}$ by a timing lights system (Fusion Sports, Sumner Park, Australia). Gates were positioned at 0 $\mathrm{m}, 5 \mathrm{~m}, 10 \mathrm{~m}$, and $20 \mathrm{~m}$, at a height of $1.2 \mathrm{~m}$ and width of $2.5 \mathrm{~m}$, to measure the $0-5 \mathrm{~m}, 0$ $10 \mathrm{~m}$, and 0-20 m intervals. Sprints over $5 \mathrm{~m}$ (Crewther et al., 2011; Lockie et al., 2013; Lockie et al., 2012), 10 m (Crewther et al., 2011; Lockie et al., 2013; Lockie et al., 2012; McBride et al., 2005), and $20 \mathrm{~m}$ (Till \& Cooke, 2009) have been used in the assessment of running speed in male athletes and PAP research. Participants began the sprint from a standing start 50 centimeters behind the start line to trigger the first gate, and were instructed to maximally sprint through all gates.

Two min after the second 20-m sprint, participants completed one of two conditions; CC or BSS (Figure 1). The first session to be completed was randomized. The $\mathrm{CC}$ involved the participant having 4 min recovery in a seated position after the warm-up (Lockie et al., 2016; Till \& Cooke, 2009). The BSS session involved the participant performing this exercise after the dynamic warm-up. As stated, the 5RM load was selected on the basis of previous research (Baker, 2007; Lockie et al., 2012; Rahimi, 2007; Till \& Cooke, 2009; Tsimahidis et al., 2010). Further, McBride et al. (2005) stated using intense resistance exercises to potentiate sprint acceleration performance, while Yetter \& Moir (2008) asserted that volume was more important than the actual load for eliciting a PAP response in maximal sprinting. Collectively, this led to the adoption of the 5RM load in this study.

After the PAP exercise, participants completed a 20-m sprint at the following time points: $\sim 15 \mathrm{~s}$, and 2, 4, 8, 12, and 16 min post intervention (Crewther et al., 2011; Lockie et al., 2016; Turner et al., 2015; Whelan, O'Regan, \& Harrison, 2014). A single sprint was performed at each time interval (Lim \& Kong, 2013; Lockie et al., 2016; Rahimi, 2007; Turner et al., 2015; Whelan et al., 2014). Participants were seated between each trial to reduce any effects of fatigue (Crewther et al., 2011; Lockie et al., 2016). The participants were also not informed as to what their preceding sprint times were to eliminate the influence of feedback. The post-test sprints were also converted to a percentage relative to the baseline sprints according to the following formula: \% Potentiation = Potentiated Variable (sprint performed at either $\sim 15 \mathrm{~s}, 2,4,8,12$, and $16 \mathrm{~min}$ ) $\div$ Unpotentiated Variable (average baseline sprints) $x 100$ (Chiu et al., 2003). A percent potentiation of $100 \%$ equaled no potentiation; greater than $100 \%$ indicated PAP; and less than $100 \%$ showed post-activation depression (i.e. fatigue) (Chiu et al., 2003).

\section{Statistical Analysis}

Statistical analyses were processed using the Statistics Package for Social Sciences (Version 22.0; IBM Corporation, New York, USA). Mean \pm standard deviation (SD) were calculated for each variable, and significance for all analyses was set at $p<0.05$. A repeated measures ANOVA ( $2 \times 7$; within-participants' factors: condition [CC, SS] x time [baseline, $\sim 15 \mathrm{~s}, 2,4,8,12,16 \mathrm{~min}]$ ) was conducted. Best potentiated sprint times for each participant, regardless of the time when it was achieved (Bevan et al., 2010), were also investigated via a 2 (condition: CC, BSS) x 2 (time: baseline, best) repeated 
measures ANOVA. Mauchly's test of sphericity was checked, and the GreenhouseGeisser correction was applied if sphericity was violated. If a significant $F$ ratio was detected, post hoc tests were conducted using the Bonferroni adjustment procedure for multiple comparisons. Effect sizes $(d)$ were calculated for each of the PAP sprints relative to the baseline, where the difference between the means was divided by the pooled standard deviations (Cohen, 1988). A $d$ less than 0.2 was considered a trivial effect; 0.2 to 0.6 a small effect; 0.6 to 1.2 a moderate effect; 1.2 to 2.0 a large effect; 2.0 to 4.0 a very large effect; and 4.0 and above an extremely large effect (Hopkins, 2004).

Spearman's correlations $(p<0.05)$ were calculated with respect to the absolute and relative strength as measured by the BSS, as well as PP and PF, and the percentage changes in the time variables at $\sim 15 \mathrm{~s}, 2,4,8,12$, and $16 \mathrm{~min}$, and the best time. The strength of the correlation coefficient $(\rho)$ was designated as per Hopkins (2013). A $\rho$ value between 0 to 0.30 , or 0 to -0.30 , was considered small; 0.31 to 0.49 , or -0.31 to 0.49 , moderate; 0.50 to 0.69 , or -0.50 to -0.69 , large; 0.70 to 0.89 , or -0.70 to -0.89 , very large; and 0.90 to 1 , or -0.90 to -1 , near perfect for relationship prediction.

\section{RESULTS}

The PAP descriptive data for the 20-m sprint performances following the CC and BSS are shown in Table 1. There were no significant main effects for the PAP conditions $\left(F_{1,4}\right.$ $=0.474 ; p=0.517)$, time $\left(F_{6,24}=1.553 ; p=0.204\right)$, or interactions between PAP conditions and time $\left(F_{6,24}=0.939 ; p=0.486\right)$ for the $0-5 \mathrm{~m}$ interval. For the $0-10 \mathrm{~m}$ interval, there were no significant main effects for the PAP conditions $\left(F_{1,4}=0.003 ; p=\right.$ $0.959)$, or interactions between PAP conditions and time $\left(F_{6,24}=1.307 ; p=0.292\right)$, which was also the case for the 0-20 m interval (PAP conditions: $F_{1,4}=0.085, p=0.785$; PAP conditions $*$ time: $\left.F_{6,24}=2.446, p=0.055\right)$. For both the $0-10 \mathrm{~m}\left(F_{6,24}=2.744 ; p=\right.$ $0.036)$ and $0-20 \mathrm{~m}\left(F_{6,24}=3.016 ; p=0.024\right)$ intervals, there was a significant main effect for time. However, the post hoc analysis indicated no significant differences between the time points for either the $0-10 \mathrm{~m}$ ( $p=0.201-1.000)$ or $0-20 \mathrm{~m}(p=0.096-1.000)$ interval.

With regards to the best potentiated $0-5 \mathrm{~m}$ time at any time point, there were no significant main effects for the PAP conditions $\left(F_{1,6}=0.474 ; p=0.517\right)$, or interactions between PAP conditions and time $\left(F_{1,6}=5.110 ; p=0.065\right)$. There was a significant main effect for time $\left(F_{1,6}=9.511 ; p=0.022\right)$, with the post hoc analysis indicating a significant reduction in sprint time, and thus potentiation of the $0-5 \mathrm{~m}$ interval. There were no significant main effects for the PAP conditions $\left(F_{1,6}=0.319 ; p=0.593\right)$, time $\left(F_{1,6}=\right.$ $3.751 ; p=0.101)$, or interactions between PAP conditions and time $\left(F_{1,6}=0.885 ; p=\right.$ 0.383 ) for the $0-10 \mathrm{~m}$ best time. This was also the case for the $0-20 \mathrm{~m}$ interval (PAP conditions: $F_{1,6}=0.327, p=0.588$; time: $F_{1,6}=0.765, p=0.415$; PAP conditions $*$ time: $\left.F_{1,6}=0.534 ; p=0.493\right)$. 
Table 1 Descriptive data (mean \pm SD) and for the 0-5 m, 0-10 m, and 0-20 m intervals in a 20-m sprint following the CC and BSS PAP conditions. Potentiated intervals (times lower than the baseline) are highlighted. Effect sizes $(d)$ were calculated relative to the baseline

\begin{tabular}{lcccc}
\hline & \multicolumn{2}{c}{$\mathrm{CC}$} & \multicolumn{2}{c}{ BSS } \\
\cline { 2 - 5 } & Time $(\mathrm{s})$ & $d$ & Time & $d$ \\
\hline $0-5 \mathrm{~m}$ & & & & \\
Baseline & $1.063 \pm 0.057$ & - & $1.074 \pm 0.040$ & - \\
$\sim 15 \mathrm{~s}$ & $1.087 \pm 0.034$ & -0.51 & $1.086 \pm 0.051$ & -0.26 \\
$2 \mathrm{~min}$ & $1.088 \pm 0.050$ & -0.47 & $1.070 \pm 0.042$ & 0.10 \\
$4 \mathrm{~min}$ & $1.081 \pm 0.060$ & -0.31 & $1.085 \pm 0.041$ & -0.27 \\
$8 \mathrm{~min}$ & $1.090 \pm 0.033$ & -0.58 & $1.075 \pm 0.033$ & -0.03 \\
$12 \mathrm{~min}$ & $1.090 \pm 0.047$ & -0.52 & $1.092 \pm 0.030$ & -0.51 \\
$16 \mathrm{~min}$ & $1.092 \pm 0.039$ & -0.59 & $1.067 \pm 0.050$ & 0.15 \\
Best & $1.060 \pm 0.056$ & 0.05 & $1.060 \pm 0.059$ & 0.28 \\
\hline $0-10 \mathrm{~m}$ & & & & \\
Baseline & $1.817 \pm 0.068$ & - & $1.817 \pm 0.061$ & - \\
$\sim 15 \mathrm{~s}$ & $1.845 \pm 0.046$ & -0.48 & $1.872 \pm 0.098$ & -0.67 \\
$2 \mathrm{~min}$ & $1.841 \pm 0.061$ & -0.37 & $1.830 \pm 0.078$ & -0.19 \\
$4 \mathrm{~min}$ & $1.830 \pm 0.082$ & -0.17 & $1.837 \pm 0.076$ & -0.29 \\
$8 \mathrm{~min}$ & $1.834 \pm 0.057$ & -0.27 & $1.829 \pm 0.066$ & -0.19 \\
$12 \mathrm{~min}$ & $1.846 \pm 0.074$ & -0.41 & $1.842 \pm 0.059$ & -0.42 \\
$16 \mathrm{~min}$ & $1.845 \pm 0.055$ & -0.45 & $1.821 \pm 0.058$ & -0.07 \\
Best & $1.808 \pm 0.073$ & 0.13 & $1.814 \pm 0.082$ & 0.04 \\
\hline $0-20 \mathrm{~m}$ & & & & \\
Baseline & $3.108 \pm 0.117$ & - & $3.109 \pm 0.101$ & - \\
$\sim 15 \mathrm{~s}$ & $3.145 \pm 0.103$ & -0.34 & $3.293 \pm 0.304$ & -0.81 \\
$2 \mathrm{~min}$ & $3.146 \pm 0.091$ & -0.36 & $3.136 \pm 0.133$ & -0.23 \\
$4 \mathrm{~min}$ & $3.130 \pm 0.136$ & -0.17 & $3.143 \pm 0.139$ & -0.28 \\
$8 \mathrm{~min}$ & $3.154 \pm 0.111$ & -0.40 & $3.136 \pm 0.121$ & -0.24 \\
$12 \mathrm{~min}$ & $3.165 \pm 0.122$ & -0.48 & $3.151 \pm 0.106$ & -0.41 \\
$16 \mathrm{~min}$ & $3.175 \pm 0.117$ & -0.57 & $3.143 \pm 0.106$ & -0.33 \\
Best & $3.117 \pm 0.122$ & -0.08 & $3.131 \pm 0.146$ & -0.18 \\
\hline & & & &
\end{tabular}

The mean BSS load was $50.41 \pm 18.02 \mathrm{~kg}$, which resulted in a mean relative strength measure of $0.65 \pm 0.23 \mathrm{~kg} \cdot \mathrm{BM}^{-1}$. Table 2 displays the correlations between $5 \mathrm{RM}$ BSS strength and the potentiated sprint performances. All significant correlations were negative, which indicated that greater strength was associated with greater sprint potentiation (i.e. a lower percentage of the baseline). There were significant correlations between absolute and relative strength (both very large) with the potentiated 0-5 sprint time at $16 \mathrm{~min}$. There were no significant correlations between strength and 0-10 m time. With regards to the 0-20 m interval, there was a very large correlation between relative strength and potentiated sprint time at $8 \mathrm{~min}$, and absolute and relative strength (both very large) with the best potentiated sprint. 
Table 2 Spearman's correlations between absolute and relative strength as measured by the 5RM BSS with percent potentiation during the $0-5 \mathrm{~m}, 0-10 \mathrm{~m}$, and 0-20 m intervals in a 20 -m sprint at $\sim 15 \mathrm{~s}-16$ min post 5 RM BSS performance. A negative correlation indicates a higher load was associated with a faster time. Significant correlations are highlighted

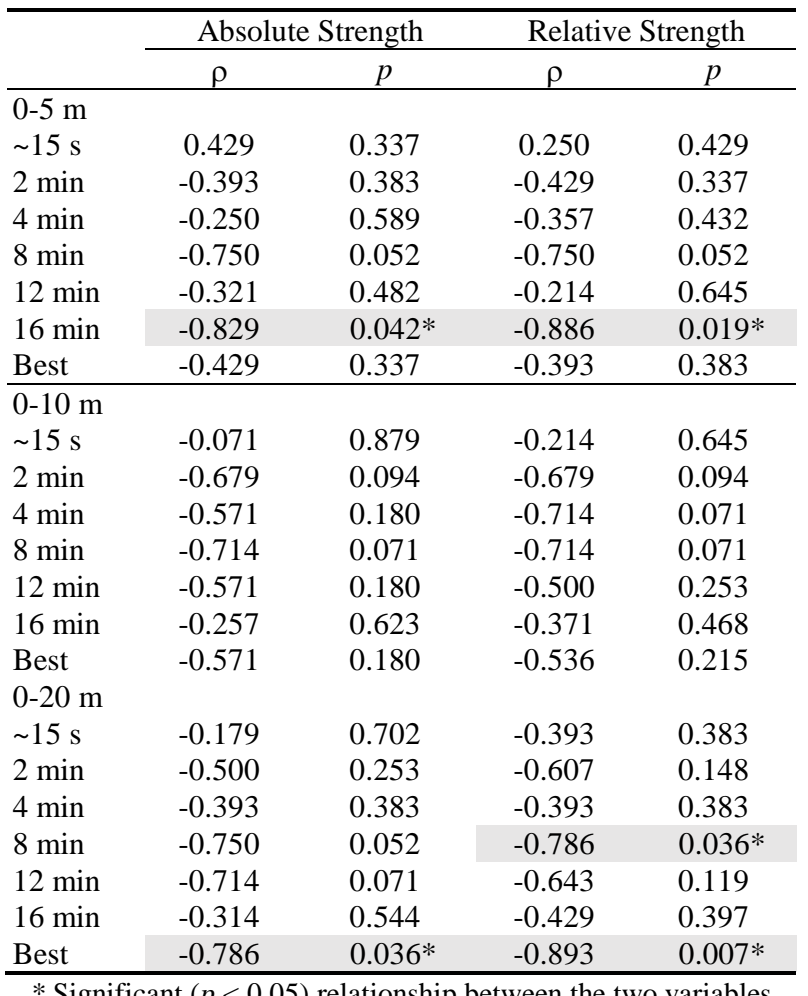

* Significant $(p<0.05)$ relationship between the two variables

PP for the left and right legs was $939.58 \pm 188.50$ and $982.46 \pm 193.72$ watts, respectively. PF for the left and right legs was $1636.59 \pm 280.29$ and $1651.72 \pm 290.45$ newtons, respectively. The correlations between these variables and potentiated sprint performances are shown in Table 3. All significant correlations were negative, which indicated that greater PP or PF was associated with greater sprint potentiation. There was a very large correlation between right-leg PP and the potentiated 0-5 $\mathrm{m}$ at $2 \mathrm{~min}$. At $8 \mathrm{~min}$, the left- (very large) and right-leg (near perfect) PF significantly related to potentiated $0-5 \mathrm{~m}$ time. 
Table 3 Spearman's correlations between left- and right-leg mean peak power (PP) and force $(\mathrm{PF})$ as measured during the $5 \mathrm{RM}$ BSS with percent potentiation during the $0-5 \mathrm{~m}, 0-10 \mathrm{~m}$, and $0-20 \mathrm{~m}$ intervals in a $20-\mathrm{m}$ sprint at $\sim 15 \mathrm{~s}-16 \mathrm{~min}$ post $5 \mathrm{RM}$ BSS performance. A negative correlation indicates greater peak power was associated with a faster time. Significant correlations are highlighted

\begin{tabular}{|c|c|c|c|c|c|c|c|c|}
\hline & \multicolumn{2}{|c|}{ Left-Leg PP } & \multicolumn{2}{|c|}{ Right-Leg PP } & \multicolumn{2}{|c|}{ Left-Leg PF } & \multicolumn{2}{|c|}{ Right-Leg PF } \\
\hline & $\rho$ & $p$ & $\rho$ & $p$ & $\rho$ & $p$ & $\rho$ & $p$ \\
\hline \multicolumn{9}{|l|}{$0-5 \mathrm{~m}$} \\
\hline$\sim 15 \mathrm{~s}$ & 0.107 & 0.819 & 0.214 & 0.645 & 0.500 & 0.253 & 0.571 & 0.180 \\
\hline $2 \min$ & -0.429 & 0.337 & -0.857 & $0.014 *$ & -0.607 & 0.148 & -0.643 & 0.119 \\
\hline $4 \min$ & -0.214 & 0.645 & -0.643 & 0.119 & -0.536 & 0.215 & -0.571 & 0.180 \\
\hline $8 \mathrm{~min}$ & -0.286 & 0.535 & -0.643 & 0.119 & -0.857 & $0.014 *$ & -0.929 & $0.003 *$ \\
\hline $12 \mathrm{~min}$ & -0.107 & 0.819 & -0.571 & 0.180 & -0.643 & 0.119 & -0.679 & 0.094 \\
\hline $16 \mathrm{~min}$ & 0.086 & 0.872 & -0.200 & 0.704 & -0.486 & 0.329 & -0.600 & 0.208 \\
\hline Best & -0.036 & 0.939 & -0.286 & 0.535 & -0.214 & 0.645 & -0.250 & 0.589 \\
\hline \multicolumn{9}{|l|}{$0-10 \mathrm{~m}$} \\
\hline$\sim 15 \mathrm{~s}$ & 0.000 & 1.000 & 0.071 & 0.879 & 0.143 & 0.760 & 0.179 & 0.702 \\
\hline $2 \min$ & -0.786 & $0.036 *$ & -0.964 & $<0.001 *$ & -0.857 & $0.014 *$ & -0.821 & $0.023^{*}$ \\
\hline $4 \min$ & -0.714 & 0.071 & -0.929 & $0.003 *$ & -0.607 & 0.148 & -0.643 & 0.119 \\
\hline $8 \mathrm{~min}$ & -0.500 & 0.253 & -0.857 & $0.14 *$ & -0.857 & $0.014^{*}$ & -0.893 & $0.007 *$ \\
\hline $12 \mathrm{~min}$ & -0.071 & 0.879 & -0.571 & 0.180 & -0.714 & 0.071 & -0.821 & $0.023 *$ \\
\hline $16 \mathrm{~min}$ & 0.714 & 0.111 & 0.371 & 0.468 & 0.029 & 0.957 & -0.143 & 0.787 \\
\hline Best & 0.107 & 0.819 & 0.000 & 1.000 & -0.143 & 0.760 & -0.214 & 0.645 \\
\hline \multicolumn{9}{|l|}{$0-20 \mathrm{~m}$} \\
\hline$\sim 15 \mathrm{~s}$ & 0.000 & 1.000 & 0.036 & 0.939 & 0.214 & 0.645 & 0.179 & 0.702 \\
\hline $2 \min$ & -0.857 & $0.014 *$ & -0.964 & $<0.001 *$ & -0.643 & 0.119 & -0.607 & 0.148 \\
\hline $4 \min$ & -0.893 & $0.007 *$ & -0.786 & $0.036^{*}$ & -0.536 & 0.215 & -0.464 & 0.294 \\
\hline $8 \mathrm{~min}$ & -0.643 & 0.119 & -0.929 & $0.003 *$ & -0.821 & $0.023 *$ & -0.857 & $0.014 *$ \\
\hline $12 \mathrm{~min}$ & -0.107 & 0.819 & -0.536 & 0.215 & -0.714 & 0.071 & -0.857 & $0.014 *$ \\
\hline $16 \mathrm{~min}$ & 0.771 & 0.072 & 0.314 & 0.554 & -0.086 & 0.872 & -0.314 & 0.544 \\
\hline Best & -0.536 & 0.215 & -0.643 & 0.119 & -0.536 & 0.215 & -0.571 & 0.180 \\
\hline
\end{tabular}

There were numerous significant relationships between PP and PF with 0-10 m time (Table 3). At $2 \mathrm{~min}, \mathrm{PP}$ and PF for both legs significantly correlated with potentiated 0-10 $\mathrm{m}$ time, with relationships ranging from very large to near perfect. There was a near perfect relationship between right-leg PP and 0-10 $\mathrm{m}$ time. There were very large relationships between right-leg PP, and left- and right-leg PF with sprint time at 8 min, and at 12 min with right-leg PF.

Several significant relationships also existed between PP and PF and 0-20 m time (Table 3). At $2 \mathrm{~min}$, the left- (very large) and right-leg (near perfect) PP correlated with potentiated 0-20 m time. PP for both legs had very large relationships with 0-20 m time at $4 \mathrm{~min}$. At $8 \mathrm{~min}$, potentiated 0-20 m sprint time had a near perfect relationship with rightleg PP, and very large relationships with left- and right-leg PF. At $12 \mathrm{~min}$, there was also a very large correlation with right-leg PF. 


\section{DISCUSSION}

This was the first study to investigate whether a $5 \mathrm{RM}$ BSS can potentiate 0-5 m, 0-10 $\mathrm{m}$, or 0-20 m sprint times in strength-trained men. In contrast to the studies' hypothesis, the results indicated that the BSS did not significantly potentiate sprint performance at any time point from $\sim 15 \mathrm{~s}$ to 16 min after the PAP protocol. Several PAP studies have indicated that certain strength exercises do not cause significant potentiating effects on sprint performance (Bevan et al., 2010; Crewther et al., 2011; Lim \& Kong, 2013; McBride et al., 2005). However, previous research has also indicated that there can be large individual variations regarding the magnitude and timing of any PAP effects (Bevan et al., 2010; Lim \& Kong, 2013; Till \& Cooke, 2009). This was the case in this pilot analysis, which likely contributed to the lack of significant differences found in sprint performance potentiation.

As a result, it is also important to consider where performance may be potentiated for the individual (i.e. the individual's best potentiated time point, and thus optimal recovery time), rather than just considering an overall mean (Nibali, Chapman, Robergs, \& Drinkwater, 2015). As an example of this, Bevan et al. (2010) found that following a 3RM back squat in male rugby players, if the best times were taken regardless of when they occurred following the PAP protocol, the results showed that $0-5 \mathrm{~m}$ and $0-10 \mathrm{~m}$ sprint times were potentiated. The results from the current study showed a tendency for sprint times to be reduced (i.e. potentiated) for the $0-5 \mathrm{~m}$ and $0-10 \mathrm{~m}$ intervals; however, the only significant result was found for the 0-5 $\mathrm{m}$ interval. Furthermore, there were no significant differences between the CC and BSS. The sample size from this pilot study (n $=7$ ) could have influenced this lack of between-condition difference. Nevertheless, the BSS could potentiate short sprint performance in select individuals. This potentiation may not be significantly different to a $\mathrm{CC}$ such as $4 \mathrm{~min}$ rest, so it is essential for the coach to monitor individual responses in their athletes. If an individual does respond positively, then a complex set involving the BSS and a sprint could be incorporated into training.

Several studies have illustrated that stronger participants are more likely to achieve PAP effects when compared to their weaker counterparts (Chiu et al., 2003; Seitz, de Villarreal, \& Haff, 2014; Suchomel, Sato, DeWeese, Ebben, \& Stone, 2016). The results from this study provided support to these assertions. The potentiation of $0-5 \mathrm{~m}$ sprint performance at $16 \mathrm{~min}$ was associated with greater absolute and relative strength. The best potentiated $0-20 \mathrm{~m}$ sprint was also significantly correlated with greater absolute and relative strength, while potentiation of $0-20 \mathrm{~m}$ time at $8 \mathrm{~min}$ was correlated with greater relative strength. However, given the potential importance of strength for the magnitude and timing of PAP (Chiu et al., 2003; Seitz et al., 2014; Suchomel et al., 2016), it was somewhat surprising that there were only 5 significant relationships out of 42 correlations between sprint potentiation and strength. For the BSS, and many exercises used to develop strength and power, it is not just the load lifted which is important, but how the load is lifted (i.e. the power and force that is produced) (Harris, Cronin, Taylor, Boris, \& Sheppard, 2010). This was true for this study when investigating the correlations between BSS PP and PF with the potentiated sprint times.

This is the first study that investigated the relationships between PP and PF measured via a linear position transducer during an exercise such as the BSS with PAP sprint responses. The use of a linear position transducer provides practical application for coaches, in that this type of 
equipment is easy to use and popular in the field (Drinkwater, Galna, McKenna, Hunt, \& Pyne, 2007; Harris et al., 2010; Lockie et al., in press). For both the PP and PF correlations, there were 10 out of 42 significant relationships. Notably, the strength of these correlations were high (very large to near perfect), and occurred for both legs and at time points ranging from 2-12 min post the BSS PAP intervention, which provided some support to the studies' hypothesis. The significant correlations found for both PP and PF at the early time points (i.e. 2-4 min for each of the intervals) was noteworthy, as stronger individuals can experience potentiation in power-based exercises sooner following a strength intervention (Seitz et al., 2014; Suchomel et al., 2016). The muscle fiber characteristics of individuals could contribute to the timing of PAP responses, and have influenced these results. Following a literature review, Seitz et al. (2014) discussed that stronger individuals displayed elevated myosin light chain phosphorylation and tend to have stronger and larger type II muscle fibers. Seitz et al. (2014) further stated that type II muscle fibers exhibited greater neural excitation in response to strength training exercises (i.e. the BSS in this study). Taken together, this indicates that those individuals who can generate greater $\mathrm{PP}$ and $\mathrm{PF}$ in an exercise such as the 5RM BSS could both potentiate sprint performance and potentiate sooner following a PAP intervention.

There are certain study limitations that should be noted. Each leg lifted the same load for the BSS. Potentially, the stronger leg for each participant could have lifted a heavier load, as the weaker leg dictated test termination. This could have influenced PAP sprint responses. The sample size for this pilot study was small $(n=7)$, so future research should feature a larger sample to confirm the results of this study. The BSS was not compared to any other exercise. The back squat has been investigated in a range of PAP and sprint studies (Bevan et al., 2010; Chatzopoulos et al., 2007; Crewther et al., 2011; Lim \& Kong, 2013; McBride et al., 2005; Rahimi, 2007; Yetter \& Moir, 2008), thus forthcoming research should compare the BSS to a bilateral exercise such as the back squat to see if sprint potentiation differs between the exercises. Only the 5RM BSS load was investigated in this research. Future studies could investigate both heavier and lighter loads for the BSS in PAP sprint research.

\section{CONCLUSION}

In conclusion, the results indicated that the BSS did not potentiate sprint performance from $\sim 15 \mathrm{~s}$ to 16 min following the intervention when considering the overall mean of the participants. However, when considering the best potentiated time, there was an improvement in 0-5 $\mathrm{m}$ sprint performance, although this was not significantly different from the CC. The correlation analyses indicated that stronger individuals could experience potentiation of 20-m sprint performance. Coaches should monitor PP and PF during a PAP exercises such as the BSS, rather than just relying on load. This is because the correlation results indicated that individuals who generated greater PP and PF potentiated 20-m sprint performance, and potentiated sooner following a 5RM BSS intervention. Future research should incorporate a greater sample size to confirm some of these findings, as well as comparing the BSS to other popular PAP strength exercises such as the back squat. 
Acknowledgement: We would like to acknowledge our participants for their contribution to the study. This research project received no external financial assistance. None of the authors have any conflict of interest. Thanks to Alyssa Stage, Tricia Liu, Fabrice Risso, DeShaun Davis, Adrina Lazar, Dominic Giuliano, Samantha Birmingham-Babauta, Ibett Torne, Megan Beiley, Jillian Hurley, and John Stokes for assisting with data collection.

\section{REFERENCES}

Baker, D. (2007). Cycle-length variants in periodized strength/power training. Strength and Conditioning Journal, $29,10-17$.

Bevan, H. R., Cunningham, D. J., Tooley, E. P., Owen, N. J., Cook, C. J., \& Kilduff, L. P. (2010). Influence of postactivation potentiation on sprinting performance in professional rugby players. Journal of Strength and Conditioning Research, 24, 701-705.

Chatzopoulos, D. E., Michailidis, C. J., Giannakos, A. K., Alexiou, K. C., Patikas, D. A., Antonopoulos, C. B., \& Kotzamanidis, C. M. (2007). Postactivation potentiation effects after heavy resistance exercise on running speed. Journal of Strength and Conditioning Research, 21, 1278-1281.

Chiu, L. Z., Fry, A. C., Weiss, L. W., Schilling, B. K., Brown, L. E., \& Smith, S. L. (2003). Postactivation potentiation response in athletic and recreationally trained individuals. Journal of Strength and Conditioning Research, 17, 671-677.

Cohen, J. (1988). Statistical power analysis for the behavioral sciences (2nd ed.). Hillsdale, New Jersey: Lawrence Earlbaum Associates.

Crewther, B. T., Kilduff, L. P., Cook, C. J., Middleton, M. K., Bunce, P. J., \& Yang, G. Z. (2011). The acute potentiating effects of back squats on athlete performance. Journal of Strength and Conditioning Research, $25,3319-3325$

Drinkwater, E. J., Galna, B., McKenna, M. J., Hunt, P. H., \& Pyne, D. B. (2007). Validation of an optical encoder during free weight resistance movements and analysis of bench press sticking point power during fatigue. Journal of Strength and Conditioning Research, 21, 510-517.

Drinkwater, E. J., Moore, N. R., \& Bird, S. P. (2012). Effects of changing from full range of motion to partial range of motion on squat kinetics. Journal of Strength and Conditioning Research, 26, 890-896.

Ebben, W. P. (2002). Complex training: a brief review. Journal of Sports Science and Medicine, 1, 42-46.

Harris, N. K., Cronin, J., Taylor, K. L., Boris, J., \& Sheppard, J. (2010). Understanding position transducer technology for strength and conditioning practitioners. Strength and Conditioning Journal, 32, 66-79.

Hodgson, M., Docherty, D., \& Robbins, D. (2005). Post-activation potentiation: underlying physiology and implications for motor performance. Sports Medicine, 35, 585-595.

Hopkins, W. G. (2004). How to interpret changes in an athletic performance test. Sportscience, 8, 1-7.

Hopkins, W. G. (2013). A scale of magnitude for effect statistics. Retrieved on May 15, 2016 from the World Wide Web: www.sportsci.org/resource/stats/index.html.

Lim, J. J., \& Kong, P. W. (2013). Effects of isometric and dynamic postactivation potentiation protocols on maximal sprint performance. Journal of Strength and Conditioning Research, 27, 2730-2736.

Lockie, R., G., Davis, D., L., Giuliano, D., V., Risso, F., G., Orjalo, A., J., Moreno, M., R., \& Lazar, A. (2016). A preliminary case analysis of the post-activation potentiation effects of plyometrics on sprint performance in women. Sport Science Review, 25, 300-319.

Lockie, R. G., Moreno, M. R., Lazar, A., Risso, F. G., Tomita, T. M., Stage, A. A., Birmingham-Babauta, S. A., Torne, I. A., Stokes, J. J., Giuliano, D. V., Davis, D. L., Orjalo, A. J., \& Callaghan, S. J. (in press). The onerepetition maximum mechanics of a high-handle hexagonal bar deadlift compared to a conventional deadlift as measured by a linear position transducer. Journal of Strength and Conditioning Research.

Lockie, R. G., Murphy, A. J., Schultz, A. B., Jeffriess, M. D., \& Callaghan, S. J. (2013). Influence of sprint acceleration stance kinetics on velocity and step kinematics in field sport athletes. Journal of Strength and Conditioning Research, 27, 2494-2503.

Lockie, R. G., Murphy, A. J., Schultz, A. B., Knight, T. J., \& Janse de Jonge, X. A. K. (2012). The effects of different speed training protocols on sprint acceleration kinematics and muscle strength and power in field sport athletes. Journal of Strength and Conditioning Research, 26, 1539-1500.

McBride, J. M., Nimphius, S., \& Erickson, T. M. (2005). The acute effects of heavy-load squats and loaded countermovement jumps on sprint performance. Journal of Strength and Conditioning Research, 19, 893-897. 
McCurdy, K., Langford, G. A., Cline, A. L., Doscher, M., \& Hoff, R. (2004). The reliability of 1- and 3RM tests of unilateral strength in trained and untrained men and women. Journal of Sports Science and Medicine, 3, 190-196.

Nibali, M. L., Chapman, D. W., Robergs, R. A., \& Drinkwater, E. J. (2015). Considerations for determining the time course of post-activation potentiation. Applied Physiology, Nutrition, and Metabolism, 40, 1163-1170.

Rahimi, R. (2007). The acute effects of heavy versus light-load squats on sprint performance. Facta Universitatis Series Physical Education and Sport, 5(2), 163-169.

Seitz, L. B., de Villarreal, E. S., \& Haff, G. G. (2014). The temporal profile of postactivation potentiation is related to strength level. Journal of Strength and Conditioning Research, 28, 706-715.

Speirs, D. E., Bennett, M. A., Finn, C. V., \& Turner, A. P. (2016). Unilateral vs. bilateral squat training for strength, sprints, and agility in academy rugby players. Journal of Strength and Conditioning Research, 30, 386-392.

Suchomel, T. J., Sato, K., DeWeese, B. H., Ebben, W. P., \& Stone, M. H. (2016). Potentiation following ballistic and non-ballistic complexes: The effect of strength level. Journal of Strength and Conditioning Research, 30 , 1825-1833.

Till, K. A., \& Cooke, C. (2009). The effects of postactivation potentiation on sprint and jump performance of male academy soccer players. Journal of Strength and Conditioning Research, 23, 1960-1967.

Tillin, N. A., \& Bishop, D. (2009). Factors modulating post-activation potentiation and its effect on performance of subsequent explosive activities. Sports Medicine, 39, 147-166.

Tsimahidis, K., Galazoulas, C., Skoufas, D., Papaiakovou, G., Bassa, E., Patikas, D., \& Kotzamanidis, C. (2010). The effect of sprinting after each set of heavy resistance training on the running speed and jumping performance of young basketball players. Journal of Strength and Conditioning Research, 24, 2102-2108.

Turner, A. P., Bellhouse, S., Kilduff, L. P., \& Russell, M. (2015). Postactivation potentiation of sprint acceleration performance using plyometric exercise. Journal of Strength and Conditioning Research, 29, 343-350.

Whelan, N., O'Regan, C., \& Harrison, A. J. (2014). Resisted sprints do not acutely enhance sprinting performance. Journal of Strength and Conditioning Research, 28, 1858-1866.

Wilson, J. M., Duncan, N. M., Marin, P. J., Brown, L. E., Loenneke, J. P., Wilson, S. M., Jo, E., Lowery, R. P., \& Ugrinowitsch, C. (2013). Meta-analysis of postactivation potentiation and power: effects of conditioning activity, volume, gender, rest periods, and training status. Journal of Strength and Conditioning Research, 27, 854-859.

Yetter, M., \& Moir, G. L. (2008). The acute effects of heavy back and front squats on speed during forty-meter sprint trials. Journal of Strength and Conditioning Research, 22, 159-165.

\section{PILOT ANALIZA: DA LI BUGARSKI SPLIT-ČUČANJ MOŽE DA POBOLJŠA UBRZANJE U SPRINTU MEĐU MUŠKARCIMA KOJI SPROVODE TRENING SNAGE?}

U ovom istraživanju ispitivali smo da je da li bi pet ponavljanja bugarskih split-čučnjeva maksimalnom snagom (5RM BSS) poboljšalo učinak na 0-5, 0-10 i 0-20 m (metar) sprintom. Sedmorica muškaraca procenjeni su 5RM BSS (transduktor postavljen linearno merio je vrhunac snage [PP] i silu $[P F]$ za svaku nogu), i završili 2 treninga postaktivacionog poboljšanja (PAP). Jedan trening imao je kontrolni uslov (CC): odmaranje 4 minuta (min); drugi 5RM BSS. Učesnici su procenjeni u sprintu sa osnovne linije, i sprintu od 15 sekundi, 2, 4, 8, 12 i 16 min post-CALE intervencije. ANOVAom za ponovljene mere $(p<0,05)$ izračunata je značajna promena u sprintu. Najbolje poboljšanje u vremenu za svaki interval upoređivano je u odnosu na sprint sa osnovne linije. Spirmanovom korelacijom ( $\rho$; $p<$ $0,05)$ izračunata je relacija između apsolutne i relativne snage, PP $i$ PF, sa procentom poboljšanja u sprintu. BSS nije doveo do poboljšanja za bilo koji interval, iako je bilo velikih individualnih varijacija. Najbolji vreme za sprint na 0-5m znatno se razlikuje od onog sa osnovne linije ( $p=0.022)$, ali nema razlike između PAP uslova. Nije pronađena značajna korelacija između snage i poboljšanja u sprint na 16 min za 0-5 m interval, i za 8 min i najbolja vremena za interval 0-20 m ( $\rho=-0.786$ do -0.893). Bilo je korelacija između PP $i$ PF za svaku nogu sa poboljšanjem u sprintu od 2-12 min u svim intervalima ( $\rho$ $=-0.786$ da-0.964). Jači pojedinci koji ostvaruju veće PP i PF u BSS 5RM će češće imati poboljšanja u performansi sprinta na 20-m.

Ključne reči: PAP, unilateralna snaga, vrhunac snage, vrhunac sile i transduktor postavljen linearno 